\title{
Anti-Integrin Monoclonal Antibody-DM4 Immunoconjugate IMGN388
}

National Cancer Institute

\section{Source}

National Cancer Institute. Anti-Integrin Monoclonal Antibody-DM4 Immunoconjugate

IMGN388. NCI Thesaurus. Code C78839.

An immunoconjug ate consisting of an anti-integrin monoclonal antibody covalently attached to the maytansinoid DM4, a derivative of the cytotoxic agent maytansine (DM1), with potential antineoplastic activity. Integrin-targ eted immunoconjug ate IMGN388 binds to tumor cell surface integrins; upon internalization, the DM4 moiety is released from the immunoconjug ate, binding to tubulin and disrupting microtubule assembly/disassembly dynamics, which may result in inhibition of cell division and cell growth of integrin-expressing tumor cells. Integrins, a class of transmembrane cell surface receptors, link the extracellular matrix (ECM) to intracellular signaling pathways that control cell proliferation and differentiation. 